\title{
A design for de-fragmentation of concrete materials to decline the vulnerability in the reconstruction of houses
}

\author{
S. Shahnoori \& L. Voorbij \\ Department of Building Technology, Delft University of Technology, \\ Delft, The Netherlands
}

\begin{abstract}
In an integrated building system optimization of the sub-systems and the segments is a key issue. Improving the structural elements and materials for a reconstruction after an earthquake is even more important than a normal construction. Because earthquakes annually cause big economic and human impacts on world's society such as losses of energy (causing depletion of natural resources in a large scale), efforts, and lives. With building destruction in seismic areas, the collapse of construction materials and their weight is the main reason for fatalities and severe injuries. Houses as the major inhabited buildings are the main subject of the collapse or damages in earthquakes. Thus, to guarantee the sustainability by an integrated design and a qualitative building system, appropriately materialization of houses is highly important in seismic areas. As the context of this study is a seismic desert city, it concentrates on increasing the efficiency of the building system in such an area. The main goal is declining the vulnerability of the inhabitants of a house by appropriately materialisation and designing for de-fragmentation.
\end{abstract}

Keywords: fiber reinforced concrete, seismic application, material defragmentation, structural safety element, externally bonded FRP.

\section{Introduction}

Material fragmentation (especially in concrete structures) that occurs during disasters is a very probable consequence of structural collapse. This does not only threats the lives of the inhabitants of the buildings but also has a huge 
environmental impact as a result of the materials losses [1]. This includes extraction of raw materials, refinement, production process, demolition and waste [2].

Earthquakes are the most destructive natural phenomena [3]. This is on the one hand due to the expansive occurrence of earthquakes across the globe and on the other hand the high frequency of it. The difference between the ground motion and the building returning to the first position causes the main destructions. Under seismic loading, integral behaviour of structural components and elements is very important [4]. For such behaviour homogenous behaviour of materials is crucial in combination with appropriate connections between building elements [5]. For a homogenous behaviour of structural element in a seismic application the ductility of concrete is very important [6].

Engineered Cementitious Composite (ECC), introduced by MIT, is a ductile concrete [7]. The ductility of this concrete is realised by reinforcing it with PVA fibres [8]. These fibres are lightweight and relatively affordable [9] too. The fiber in concrete should be effective in restraining drying shrinkage or other cracking, even after the first 24 hours. Their modulus of elasticity need (for structural application) not to be less than that of concrete, and should be stiffer than the concrete [9]. In addition to its resistance to fatigue, the PVA-ECC is 500 times more resistant to cracking and $40 \%$ lighter in weight than traditional concrete. Besides, because of the optimized chemical bond strength of PVA fibers to cement the resulted composite with perfect shear resistant is a durable structural material [10]. Therefore, the PVA-ECC is a good alternative concrete for seismic areas [11]. However, to ensure materials de-fragmentation, in both the ECC and the conventional concrete, improvement of the concrete composites is important. Therefore, the influences of different versions of PVA on the basic mechanical properties of concrete are being investigated. Nevertheless, appropriately designing and detailing the structural elements can be significantly effective. For further improvement of structural concrete, application of qualified externally supporting materials have to be developed.

Structural materials collapse and fragment after suffering a certain level of force. This creates the risk for the inhabitants of being hit and trapped by fragments. Therefore, to decline the vulnerability of the inhabitants an additional factor such as covering a safety layer around the concrete to postpone the fragmentation was the main purpose of this study. Reference material for such application was FRP (Fibre Reinforce Polymer). First the basic material was implemented without any reinforcement and then for the second phase the epoxy matrix was reinforced with glass fibers. Finally in the third phase single layers of bonding materials were compared with the multi-layer ones.

\subsection{FRP as a safety factor}

FRP composites have high strength-to-weight ratio and corrosion resistance, and are easy to fabricate. Although it is a rather new area, FRP technology is being applied in a large range of instruments and materialization. Some important applications of these materials are in the marine, aeronautic and aircraft industry, in addition to fishing rods, tennis rackets, and golf and ski equipments. 
Application of FRP composites in building technology concentrates on two areas: As externally bonded laminates to for instance flexural strengthening concrete elements [12] and for the repair and rehabilitation of concrete (infra)structures in which it is proved to be a better solution than the steel plates used up to now [13].

This study concentrates on the application of externally bonded FRP in a new building construction for the purpose of de-fragmentation which are both new approaches. For such purpose two important issues should be taken into account. The first is the type of safety materials and their combination, and the other one is the method of veneering. There are several methods for bonding FRP around concrete. Examples of these bonding techniques are to use a separate adhesive, using steel powder-actuated (PA) and expansion anchors (EA), or by the wet layup process that means bonding and curing in-situ directly through the epoxy [14]. For this study the wet layup process was adopted.

Many studies concentrate on the field of externally bonded FRP plates for enhancing the existing concrete structures or infrastructures. Lopez [15], Brosens et al. [16], Ignoul et al. [17], Leung and Pan [18], McSweeney et al. [12] studied different aspects or approaches in this field. However, most of these studies are to enhance the existing buildings and not for using it as a strategy for new buildings. Furthermore a scientific study into the possibilities of using externally bonded FRP as a safety material to delay the time of fragmentation of a concrete structural element could not be found.

This paper focuses on the design and materialisation for such an application. This includes investigation and selection between the 10 materials for bonding. Therefore, first shortly influences of the size of PVA on some mechanical properties of the ECC (i.e. in 6 alternatives) are looked through. Secondly, feasibility of adding the safety factor (to obtain the delay of fragmentation or design for de-fragmentation) for concrete elements in houses in earthquakes as the main point of the study will be investigated.

\section{Method}

The study is dividable into two main branches of:

1. Investigation and optimization of the fibers in the basic material.

2. Design and implementation of the safety element (main point of the study).

Therefore, first for observation of physical characteristics of the resulted concrete such as mortar flow and workability, fibre's distribution, segregation, solidification and drying process, shrinkage, with different versions of PVA fibres (shown in table 1.), several mixes have been made. These experiments include 14 sets of specimens.

Table 1: The versions of the PVA which are distinct by their length.

\begin{tabular}{|l|l|l|l|l|l|l|}
\hline \multicolumn{1}{|c|}{ PVA } & 6 & 8 & 12 & $6 \& 8$ & $6 \& 12$ & $8 \& 12$ \\
Dimension & & & & & & \\
\hline Length $(\mathrm{mm})$ & 6 & 8 & 12 & $(6+8)$ & $(6+12)$ & $(8+12)$ \\
\hline Diameter $(\mu \mathrm{m})$ & 26 & 39 & 39 & $(26+39)$ & $(26+39)$ & $(39+39)$ \\
\hline
\end{tabular}


The resulted concrete were tested for compressive, tensile, and three point bending moment, to compare the mechanical properties and to observe and investigate the process of crack growth fibres pull-out and concentration) during the loading processes (figure 1(a) and 1(b).

(a)

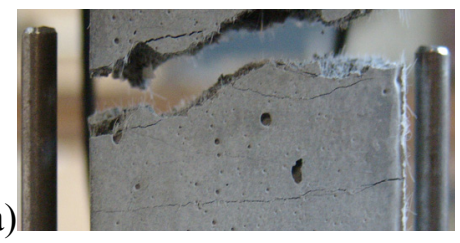

(b)

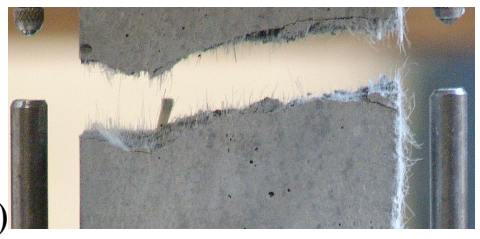

Figure 1: (a) Cracking process, (b) fibres' pull-out and concentrations on the surface.

Dimensions of 167 prisms for compressive and 3 point bending moment tests were $160 \times 40 \times 40 \mathrm{~mm}$, and $21 \mathrm{dog}$-bone tensile specimens $200 \times 60 \times 5040 \mathrm{~mm}$.

The second part of the work for veneering the conventional concrete samples, first, a concrete cylinder with a radius of $65 \mathrm{~mm}$ was covered by polyester (polypol PS60), with a thickness of about $1.5 \mathrm{~mm}$. The liquid polyester was mixed with hardener (Polyester-PigmentPasta) and brushed on the concrete. The second cylinder with the same diameter was coated with silicone rubber SA10 with an average thickness of about $5 \mathrm{~mm}$ using a cylindrical card board mould. In the third sample of coating the polyester was reinforced with $4 \mathrm{~mm}$ chopped glass fibres. To observe the collapse process, these three (the first row of table 3 ) were compared with samples without coating materials in the compressive testing. For optimization, several materials in single or multi-layers were applied to bond the concrete specimens for the same observations in addition to investigate the adhesion and interface between concrete samples and the bonded materials. For casting these bonding materials around the concrete, PVC cylindrical moulds have been used.

\begin{tabular}{|l|l|l|}
\hline & Three stages of feasibility of coating on the collapse process \\
\hline $\begin{array}{l}\text { Externa. } \\
\text { bonded } \\
\text { concrete } \\
\text { samples }\end{array}$ & & \\
\hline Materia: & 1.Poly-pol PS60 2.Sil/Rub Shore A10 3.glas.fib4+polypolPS60 \\
\hline $\begin{array}{l}\text { Casting, } \\
\text { de.moul } \\
\begin{array}{l}\text { And } \\
\text { polish. } \\
\text { process }\end{array}\end{array}$ & \\
\hline & Mould prepar+ plac. casting de-moulding polish. for testing \\
\hline
\end{tabular}

Figure 2: $\quad$ First and second phase of bonding process on the concrete samples. 
These materials are being applied with the following names: - Polyester, GFRP $=$ Glass Fiber Reinforced Polyester, - SA $10=$ Silicon with a Shore of A10, - PU60=Poly Urethane rubber with a Shore of 60, -GFRSA10=Glass Fiber Reinforced Silicon with a Shohre of 10, - GFRPUA60=Glass Fiber Reinforced Poly Urethane, Shore 60 including 3 versions of Glass fibers: • chopped, - woven, and $\bullet$ compressed (similar to woven) multi-directional long fibers - GFRP+ SA 10, and - GFRP+ PUA60.

\section{Results}

Two groups of the results are:

1. Most of the groups of specimens were de-moulded (due to the drying and hydration process) at least after 3 days. shortly after the casting a thick liquid was observed, but in about 2-4 hours, the liquid was thinner again. Other relevant results of the first part are summarised in table 2. in which the strengths are only for comparison with a scientific approach.

Table 2: $\quad$ Results of mechanical tests and related observations.

\begin{tabular}{|c|c|c|c|c|}
\hline & \multicolumn{2}{|l|}{ Highest in: } & \multicolumn{2}{|l|}{ Lowest in: } \\
\hline & Specimen & Group & Speci. & Group \\
\hline $\begin{array}{l}\text { Mortar flow } \\
\text { PVA 8mm }\end{array}$ & - & $\begin{array}{l}\text { 1.Basic }(150 \mathrm{~m} \\
\mathrm{m}) \\
\text { 2.PVA } 6+8 \\
\text { RC }(140 \mathrm{~mm})\end{array}$ & - & $\begin{array}{l}\text { PVA } 8+12 \text { RC } \\
(125 \mathrm{~mm})\end{array}$ \\
\hline Segregation & - & PVA $8+12$ RC & - & $\begin{array}{l}\text { 1. Basic } \\
\text { 2. PVA } 6+8 \\
\text { RC }\end{array}$ \\
\hline $\begin{array}{l}\text { Fiber } \\
\text { concentration }\end{array}$ & - & $\begin{array}{l}\text { On the surface } \\
\text { of PVA } 6+8 \\
\text { RC }\end{array}$ & - & PVA12 \\
\hline \multirow{3}{*}{$\begin{array}{l}\text { Strength: } \\
\text { 3point.bending: } \\
\text { (kN) } \\
\text { Compression: } \\
\text { Tension: }\end{array}$} & $6+8(10.24)$ & $\begin{array}{l}\text { PVA } 6+8 \text { RC } \\
(8.59,9.28, \\
\text { and } 9.35)\end{array}$ & PVA8 (5.09) & $\begin{array}{l}\text { 1. basic (4.35) } \\
2 . \text { PVA } 8 \\
(5.09 \text {, and } \\
5.87)\end{array}$ \\
\hline & $\begin{array}{l}\text { PVA8 (- } \\
106.357)\end{array}$ & $\begin{array}{l}\text { PVA 6 RC (- } \\
102.53 \\
-98.169)\end{array}$ & $6+8(-55.952)$ & $\begin{array}{l}\text { PVA 6+8 (- } \\
65.875,- \\
55.952 \text {, and - } \\
78.404)\end{array}$ \\
\hline & $\begin{array}{l}\text { PVA12 } \\
(5.805)\end{array}$ & $\begin{array}{l}\text { PVA } 8(3.833 \text {, } \\
\text { and } 4.253)\end{array}$ & $6+8(2.466)$ & $\begin{array}{l}\text { 1. basic } \\
(0.255) \\
2.6+8(3.325, \\
3.567, \& \\
4.167) \\
\end{array}$ \\
\hline
\end{tabular}

PVA6,8, 12...RC=concrete reinforced with PVA with a length of $6,8,12, . . \mathrm{mm}$.

Basic $=$ concrete with the same ingredients minus fibers or other reinforcements.

2. For the second part of this study (i.e. feasibility of externally bonding the concrete for de-fragmentation) results are shown in the figure 3. 


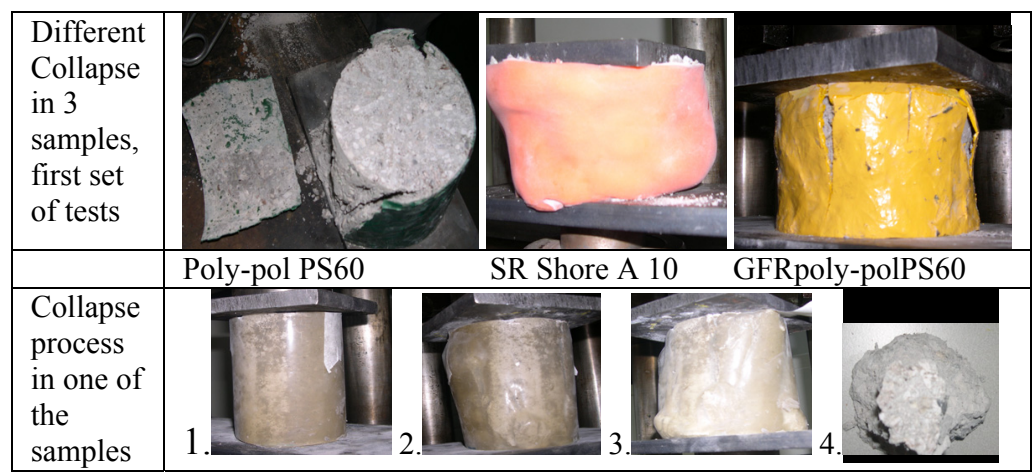

First row: the collapse type in 3 samples with 3 types of bonding materials.

Second row: the collapse process in the bonded Polyurethane rubber concrete.

Figure 3: Collapse process and behaviour of externally bonded materials on concrete samples in compressive tests (comparative).

(a)

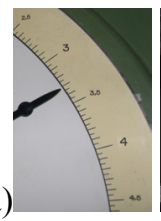

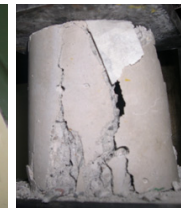

(b)

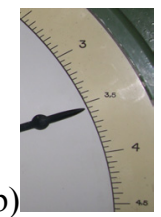

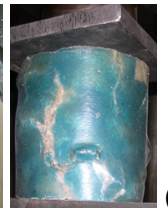

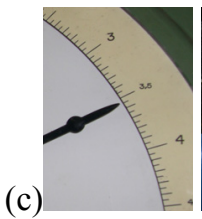

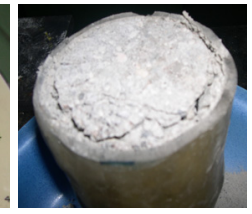

Figure 4: Improvement of the compressive strength by externally bonding the concrete sample with FRP materials.

Hence, the basic concrete sample failed earlier than that in the bonded samples. The strength growth in the latter samples is shown in figure 4 .

In table 3 a summary of comparative results of the experiments for the materials de-fragmentation has been illustrated.

\section{Discussion}

Experiments in this study did not show a considerable pull-out of fibres. This was realised due to the molecular bond of the PVA fibers with the concrete during hydration. Li [19] points the PVA to have a controlled interface bond with mortar. Suzuki et al. [20] discusses that the most improved resistant to the failure of fiber reinforced brittle matrix composites is in their superb fracture energy arising mainly from the frictional fiber pull-out process during the main crack extension. This can be regarded for the PVA-ECC that it is an advanced composite to avoid the crack extension in a building structure. The low ratio of the PVA used in the ECC (i.e. 2\%), that cause less influence on some other properties of the concrete, further proves the advantages of the PVA [21]. The main difference between the specimens with and without PVA in this study is regarded to the point that $\mathrm{Li}$ [11] states as 'PVA provides up to 500 times the tensile strain capacity of fiber-reinforced concrete'. The ECC lacks coarse 
aggregates that tend to adversely affect the unique ductile behaviour of concrete [22]. Hence, low w/c ratio (i.e. less than 0.5 ) offers higher mechanical properties, such as compressive strength while some other properties such as workability are not affected.

Table 3: $\quad$ Comparison of values in the alternative bonding materials.

\begin{tabular}{|l|l|l|l|l|l|l|}
\hline $\begin{array}{l}\text { Coating } \\
\text { materials }\end{array}$ & $\begin{array}{l}\text { Lupporting } \\
\text { Level }\end{array}$ & Thickness & Bonding & Flexibility & Material use $\begin{array}{l}\text { Product } \\
\text { simplicity }\end{array}$ \\
\hline Polyester & - & +++ & ++ & -- & ++++ & ++++ \\
\hline GFRP & + & +++ & ++ & - & ++ & ++ \\
\hline SA10 & ++ & -- & -- & ++++ & +++ & +++ \\
\hline PUA60 & ++ & - & +++ & +++ & +++ & +++ \\
\hline GFRA10 & ++ & - & -- & +++ & ++ & ++ \\
\hline $\begin{array}{l}\text { Chopped } \\
\text { GFRPU } \\
\text { A60 }\end{array}$ & +++ & + & ++++ & +++ & ++ & ++ \\
\hline $\begin{array}{l}\text { Woven } \\
\text { GFRPU } \\
\text { A60 }\end{array}$ & +++ & + & ++++ & ++ & + & + \\
\hline $\begin{array}{l}\text { Compres } \\
\text { sed } \\
\text { GFRPU } \\
\text { A60 }\end{array}$ & +++ & + & ++++ & ++ & + & + \\
\hline $\begin{array}{l}\text { GFRP+S } \\
\text { A10 }\end{array}$ & ++ & - & ++ & ++ & - & - \\
\hline $\begin{array}{l}\text { GFRP+P } \\
\text { U60 }\end{array}$ & ++ & + & ++ & ++ & - & - \\
\hline
\end{tabular}

The highest value is ++++ and the lowest value is --.

Level of support= ability of the bonding material to keep the concrete from falling apart.

The results of testing various length of PVA in the ECC in several sets, similar to the study of Kanda and Li [23], proved that the compressive strength of concrete is less influenced when changing the length of the fibres in the concrete mix. However, the range of these lengths of fibres is limited (between $6 \mathrm{~mm}$ and $12 \mathrm{~mm}$ ). Some differences between the mechanical properties of the resulted composites were recorded. However, sensitivity of the ECC and the proportions of the specimens (small moulds are more vulnerable from the environment) are arguable.

The brittleness increases when the compressive strength of the concrete goes up [24], which poses potential danger and a limitation for high strength concrete [10]. However, using the PVA fibers, declining brittleness of the concrete, offers a concrete that can be compressively strengthened while the material is still ductile. In the tensile test after the cracking, even when the crack is relatively large, the results do not show a sudden change. First, because these concretes, based on fundamental micromechanical properties, strain- hardens rather than tension-soften [10]. The first crack does not open up to a rupture as fibres are not considerably pulled-out or ruptured and the stress carrying capacity does not decrease. Similar to the study of Wang and Li [25], no considerable pull-out was 
found during the mechanical tests. This can be referred to the nature of PVAECC, in which because of the tendency of the fibre to bond strongly to the cementitious matrix, the fibres are apt to rupture instead of pull-out [25].

However, as it was mentioned, the main purpose of this study is to decrease vulnerability of inhabitant of a house by implementing an appropriate qualified structural material in addition to bonding this material with FRP as safety factor. This safety element is to create a short difference between the time of the earthquake and the time of materials fragmentation.

For which the results of the experiments showed that even in the cases that the concrete, for instance, under the compression, entirely collapses, with the FRP it does not fall apart. This was seen not only in the finalized material but also in many of the alternative composites that were tested (GFR-PUR, Thick layer of SR, GFRP+PUR, GFRP+SR, GFRPUR). However, some other factors involved in the design for safety bonding, such as adhesion or bonding property, fabrication, economy, are involved in the materials selection. Although increasing the strength was not the main purpose of this study, analogous to the study of Wu and Sun [26], Bank and Arora [27], and Kim and Hefferman [28] it was proven that this externally bonding of the concrete elements can improve some other mechanical properties such as strength.

Similarly to the study of Leung and Pan [18], the failure in many cases occurs through the de-bonding that mainly initiates from the bottom of a major flexural crack in the concrete. In more than 20 samples the failure was dominated by the friction part from which the concrete was cracked. However, the argument of Leung and Pan [18] about aggregates does not apply for this study, because the tailoring engineered concrete includes very fine ingredients and acts homogenously. As a result of the whole experiments, the failure was not considerably related to the strength of the concrete but to the bonding properties. Some other studies such as Lopez [15], McSweeney and Lopez [12] have also obtained similar results. However it should be considered that as surface strength is more effective in the failure than the strength of the concrete; the surface should be well prepared. Leung and Pan [18] summarizes the effectiveness of FRP bonding in (i) surface preparation of concrete; (ii) the type of adhesive; (iii) geometric factors, such as FRP bond length, thickness of FRP plate, FRP width etc; (iv) interfacial fracture energy. However, these are for strengthening the concrete elements not for de-fragmentation. Although stronger combination of materials may indirectly relate the de-fragmentation, in this study the delay between the collapse of the concrete and failure of the bonded element is the main purpose. During the experimental works analogous to the study of Brosens et al. [16], influence of geometry on the bonding and the quality of FRP bonding for different forms and shapes was observed. In the samples that the bonding FRP was fabricated and then put on the concrete a non-homogenous de-bonding process under the loading has been observed that analogous to the study carried out by Ignoul et al [17], proves the sensitivity of bonding method and the interface between the concrete and the FRP.

Between the applied samples in this study the GFRPUR (Glass Fiber Reinforced Poly Urethane Rubber) efficiently holds the collapsed materials. It 
bonds with the concrete element and is an available material that its fabrication is also an advantage. Although the precise type of the FRP is going to be further developed, it can generally be concluded that FRP showed perfect potential for the purpose of this study. This quality makes it useful not only for ECC but also for the conventional concrete even more effectively. Hence this externally bonding will ease cleaning of the rubbles especially in a destructive earthquake. Furthermore, with these safety materials the reuse and recycling is one step further in the phase of collecting the rubbles and separation process. Furthermore, they increase the durability of the concrete at least from the weathering. Therefore, it has additional advantages of sustainability and durability for the resulted structure. Finally, the weight of these composites is very low that is very significant especially for a seismic application.

\section{Conclusions and recommendations}

For materialization of structure of houses in seismic areas the engineered cementitious concrete reinforced with PVA fibers is a good alternative. In between the types of PVA fibers presented in this study, specimens of concrete reinforced with PVA $6+8$ (i.e. $6 \mathrm{~mm}+8 \mathrm{~mm}$ length) showed better results for such application. Furthermore, experimental work on the PVA-ECC shows a sensitive approach, which is sometimes different from the simulations and modelling, available in the literature and visualizations.

To decline vulnerability of the inhabitants of a house in seismic desert towns, externally bonding the concrete elements, at least in the critical spots of the structure, is a good solution. This bonding will postpone the time of collapse and will create opportunity for the inhabitant to rescue themselves from being trapped under the rubbles.

Externally bonded FRP is significantly effective for de-fragmentation of concrete for a short time after the structure meet the load bearing limits. A good adhesion or high bonding property is very important to avoid failure initiated from interfacial problems. Hence the surface of the concrete should not create extra influences on the load transfer especially in the interfacial area.

The FRP materials need to be further optimized and prototypes need to be made with larger dimensions and need to be tested for realization (rather than laboratory application). Finally, production method and fabrication need to be further argued in the next step. The ratio of the reinforcing fibres for the FRP needs to be optimized.

\section{References}

[1] Shahnoori, S., and Voorbij, L.; Reinforced Concrete Composite for structure of houses in Seismic desert cities; Proc. 11DBMC Durability of Building Materials ands Component; Istanbul, Turkey, 11-14 May 2008

[2] Hendriks Ch. F. Durable and sustainable construction materials and the building cycle, Best, Aeneas, 2002, ISBN 90-75365-49-7 
[3] NHM, 2005. Natural Hazard Management, Centre for Earth Science Study (CESS), 2005.

[4] Shahnoori, S. And Voorbij, L.; Technological Cooperation for a Qualitative Structure, Proc. IASS Shell and Special Structure, 3-6 December 2007 Venice, Italy

[5] VROUWENVELDER, A. C. W. M., 2006. Preparation for the Euro Code 08, Earthquake Engineering, International course at the Faculty of Civil Engineering, Delft University of Technology, 2006

[6] Fischer, G. And Li, V.; Ultra-Ductile Engineered Cementitious Composites for seismic resistant structures, Proceedings of the fib 2003 symposiumMay 6-8, Athens, Greece

[7] Li, V. 2004. Strategies for high performance fiber reinforced composites development, p.p. 93-98. International Workshop on Advanced Fiber Reinforced Concrete at Bergamo, Italy, September 24-25, 2004.

[8] Lin, Z., and Li, V.; Crack bridging in fiber Reinforced Cementitious Composites with slip-hardening; J. Mechanics and Physics of solids, 1997, ISSN: 0022-5096, 45 (5) 763- 787

[9] Kuraray. Press releases: Nycon, Kuraray Introduce Bendable Concrete to North America, New York, NY- February 1, 2007.

[10] Li, V., and Kanda, T.; Engineered Cementitious Composites for Structural Applications; ASCE Journal Materials in Civil Engineering, Vol. 10, No. 2, pp. 66-69, 1998

[11] Li, V. C. 'Nycon, Kuraray Introduce Bendable Concrete to North America', New York, NY- February 1, 2007.

[12] McSweeney, B. and Lopez, M. FRP-Concrete Bond Behaviour: A Parametric Study through Pull-Off Testing

[13] Van Gemert, D., Ignoul, S., Brosens, K. Strengthening of Concrete Construction with Externally bonded Reinforcement: Design Concept and case studies, IMTCR 2004, University of Lecce, Italy, June 6-9 2004.

[14] Bakis, C. E., Bank, L. C., Brown, V. L, ..., 'Fiber-Reinforced Polymer Composites for Construction- State-of-the-Art Review'. Journal of Composites for Construction, V. 6, 2002, PP. 73-87

[15] Lopez, M. "Study of the Flexural Behaviour of Reinforced Concrete Beams Strengthened by Externally Bonded Fiber Reinforced Polymeric (FRP) Laminates." PhD Thesis University of Michigan, 2000.

[16] Brosens, K., Ignoul, S., and Van Gemert, D. Hybrid Strengthening techniques for retrofitting of warehouses: development and case studies, WTA-Colloquium - Braunschweig, 6-8 March 2002

[17] Ignoul, S., Brosens, K., and van Gemert, D. 2003. Strengthening of concrete constructions with externally bonded reinforcement: design concepts and case studies. First International Conference on Concrete Repair, St. Malo, France, 15-17 July, 2003.

[18] Leung K. Y. and Pan, J. Effect of concrete composition on FRP/concrete bond capacity in Structures (BBFS 2005), Proceedings of the International Symposium on Bond Behaviour of FRP 
[19] Li, V. 2007. 'PVA-ECC in the news' by Hitssquad, Monday November 26, 2007

[20] Suzuki, T., S., Sato, M., Sakai, M. 'Fiber pullout processes and mechanisms of a carbon fiber reinforced silicon nitride ceramic composite,' May 1992, p.p. 2869-2875.

[21] Li, V., and Lepech, M.; General Design assumptions for engineered cementitious composites (ECC), International RILEM workshop on High performance fiber reinforced cementitious composites (HPFRCC)in structural applications Honolulu, Hawai'i, 23-26 May 2005

[22] Stang, H.; Li, V.; Extrusion on ECC-Material, in Proc. High performance fibre reinforced cement composite3 (HPFRCC); 1999, p.p. 203-212

[23] Kanda, T., and Li, V.; Interface Property and Apparent Strength of highStrength Hydrophilic Fiber in Cement Matrix; Journal of Materials in Civil Engineering, February 1998, p.p. 5-13

[24] Hillerburg, A. The Theoretical Basis of a Method to Determine the Fracture Energy Gf of concrete,' Journal of Materials and Structure, V. 18, No. 106, 1985, pp. 291-296.

[25] Wang, S., and Li, V. Tailoring of PVA fibre/matrix interface for engineered cementitious composites (ECC), engineering with fibres, Loughborough, 2003

[26] Wu, H. C. and Sun, P. Fibre reinforced cement based composite sheets for structural retrofit, proc. International symposium on Bond Behaviour of FRP in structures (BBFS 2005); p.p. 343-348.

[27] Bank, L. C., and Arora, D.; Analysis of RC beams with mechanically fastened FRP (MF-FRP) strips; Journal of Composite Structures V. 79, 2007, p.p. 180-191.

[28] Kim, Y. J., Hefferman, P. J.; Fatigue behaviour of externally bonded Strengthened Concrete Beams with Fiber-Reinforced polymers: State of the Art; Journal of Composite for construction, p.p. 246-256, May/June 2008 